Environment Conservation Journal 14(3) 173-176, 2013

ISSN 0972-3099 (Print) 2278-5124 (Online)

Abstracted and Indexed

\title{
Historical perspective and importance of micribiology in modern era
}

\section{Anjali Sethi $\square$ and Molly Madan}

Received: 08.08.2013

Revised: 16.09.2013

Accepted: 22.10.2013

\begin{abstract}
This paper introduces the historical view of microbiology and discusses the importance of microorganisms not only as causative agents of disease but also as important contributors to food production, antibiotic manufacture, vaccine development, and environmental management. Microbiology contributed significantly to the development of new branches like biochemistry. Genetics and molecular biology. It presents a brief history of the science of microbiology, an overview of the microbial world, a discussion of the scope and relevance of microbiology in today's society, and predictions about the future of microbiology.
\end{abstract}

Keywords: Germs, historical perspective, infection, microbiology, micro-organism, medicines, molecular biology, recombinant technology.

\section{Introduction}

Microbes are causative agents of many diseases was an enigma for the intellectual people. Microbiology began when people learn to grind lenses from pieces of glass and combine them to produce magnifications greater enough to enable microbes to be seen. The Germ theory of disease was established by Robert Koch, Louis Pasteur and De Bary. Thus, there was beginning of golden period of microbiology in the western hemisphere. Microbiology (from Greek, mīkros, "small"; bios, "life"; and -logia) is the study of microscopic organisms, which are defined as any living organism that is either a single cell (unicellular), a cell cluster, or has no cells at all (acellular) (Madigan, 2006). This includes eukaryotes, such as fungi and protists, and prokaryotes. Viruses and prions, though not strictly classed as living organisms, are also studied. Microbiology typically includes the study of the immune system; immune systems interact with pathogenic microbes also (Rice, 2007).

History of Microbiology:

Microbiology has had a long, rich history, initially centered in the causes of infectious diseases but now including practical applications of the science.

Author's Address

Department of Microbiology, Swami Vivekanand Subharti

University, Meerut (U.P.)

Email: anjalisethimrt@yahoo.co.in
As far as Vedic Bhārat is concerned, the Germ theory of diseases was first established by Vedic Rishis and was recorded in Vedas. In fact, Vedas are first text in the world to record nexus between microbes and disease. Rigveda, Yajurveda, and Atharvaveda followed by Āyurvedas provide rich insight into microbial sciences that existed in Bhārat many thousands of years ago. In Rigveda (1/191), Rishi Agastya pinpoints out that there are two types of poisonous creatures viz. those exceedingly poisonous and others are less poisonous. Of them, some are visible venomous, while others are invisible one. Some of them live in water, while others live on earth. Perhaps Rishi Agastya is the first person to state that invisible creatures are also toxin producers. $\mathrm{He}$ also prescribes antidotes as remedy for the poison. The existence of microorganisms was hypothesized for many centuries before their actual discovery. The existence of unseen microbiological life was postulated by Jainism which is based on Mahavira's teachings as early as 6th century BCE (Dundas Paul, 2002). Paul notes that Mahavira asserted existence of unseen microbiological creatures living in earth, water, air and fire (Dundas Paul, 2002). Jain scriptures also describe nigodas which are submicroscopic creatures living in large clusters and having a very short life and are said to pervade each 
and every part of the universe, even in tissues of plants and flesh of animals (Jaini P, 1998). The Roman Marcus Terentius Varro made references to microbes when he warned against locating a homestead in the vicinity of swamps "because there are bred certain minute creatures which cannot be seen by the eyes, which float in the air and enter the body through the mouth and nose and thereby cause serious diseases." In 1546 Girolamo Fracastoro proposed that epidemic diseases were caused by transferable seedlike entities that could transmit infection by direct or indirect contact, or vehicle transmission.Early history of microbiology, historians are unsure who made the first observations of microorganisms, but the microscope was available during the mid-1600s, and an English scientist named Robert Hooke made key observations. He is reputed to have observed strands of fungi among the specimens of cells he viewed. In the 1670 s and the decades thereafter, a Dutch merchant named Anton van Leeuwenhoek made careful observations of microscopic organisms, which he called animalcules. Until his death in 1723, van Leeuwenhoek revealed the microscopic world to scientists of the day and is regarded as one of the first to provide accurate descriptions of protozoa, fungi, and bacteria. After van Leeuwenhoek died, the study of microbiology did not develop rapidly because microscopes were rare and the interest in microorganisms was not high. In those years, scientists debated the theory of spontaneous generation, which stated that microorganisms arise from lifeless matter such as beef broth. This theory was disputed by Francesco Redi, who showed that fly maggots do not arise from decaying meat (as others believed) if the meat is covered to prevent the entry of flies. An English cleric named John Needham advanced spontaneous generation, but Lazzaro Spallanzani disputed the theory by showing that boiled broth would not give rise to microscopic forms of life. Louis Pasteur worked in the middle and late $1800 \mathrm{~s}$. He performed numerous experiments to discover why wine and dairy products became sour, and he found that bacteria were to blame. Pasteur called attention to the importance of microorganisms in everyday life and stirred scientists to think that if bacteria could make the wine "sick," then perhaps they could cause human illness. Pasteur had to disprove spontaneous generation to sustain his theory, and he therefore devised a series of swan-necked flasks filled with broth. He left the flasks of broth open to the air, but the flasks had a curve in the neck so that microorganisms would fall into the neck, not the broth. The flasks did not become contaminated, and Pasteur's experiments put to rest the notion of spontaneous generation. His work also encouraged the belief that microorganisms were in the air and could cause disease. Pasteur postulated the germ theory of disease, which states that microorganisms are the causes of infectious disease. Pasteur's attempts to prove the germ theory were unsuccessful. However, the German scientist Robert Koch provided the proof by cultivating anthrax bacteria apart from any other type of organism (Singh, 2009).

\section{Development of Microbiology}

In the late 1800s and for the first decade of the 1900 s, scientists seized the opportunity to further develop the germ theory of disease as enunciated by Pasteur and proved by Koch. There emerged a Golden Age of Microbiology during which many agents of different infectious diseases were identified. Many of the etiologic agents of microbial disease were discovered during that period, leading to the ability to halt epidemics by interrupting the spread of microorganisms. Despite the advances in microbiology, it was rarely possible to render life-saving therapy to an infected patient. Then, after World War II, the antibiotics were introduced to medicine. The incidence of pneumonia, tuberculosis, meningitis, syphilis, and many other diseases declined with the use of antibiotics. Work with viruses could not be effectively performed until instruments were developed to help scientists see these disease agents. In the 1940s, the electron microscope was developed and perfected. In that decade, cultivation methods for viruses were also introduced, and the knowledge of viruses developed rapidly. With the development of vaccines in the 1950s and 1960s, such viral diseases as polio, measles, mumps, and rubella came under control (Singh, 2009).

\section{Importance of Microbiology}

Whilst there are undoubtedly some who fear all microbes due to the association of some microbes with various human illnesses, many microbes are 
also responsible for numerous beneficial processes such as industrial fermentation (e.g. the production of alcohol, vinegar and dairy products), antibiotic production and as vehicles for cloning in more complex organisms such as plants. Scientists have also exploited their knowledge of microbes to produce biotechnologically important enzymes such as Taq polymerase, reporter genes for use in other genetic systems and novel molecular biology techniques such as the yeast two-hybrid system. Bacteria can be used for the industrial production of amino acids. Corynebacterium glutamicum is one of the most important bacterial species with an annual production of more than two million tons of amino acids acids, mainly L-glutamate and L-lysine (Burkovski, 2008).A variety of biopolymers, such as polysaccharides, polyesters, and polyamides, are produced by microorganisms. Microorganisms are used for the biotechnological production of biopolymers with tailored properties suitable for high-value medical application such as tissue engineering and drug delivery. Microorganisms are used for the biosynthesis of xanthan, alginate, cellulose, cyanophycin, poly (gamma-glutamic acid), levan, hyaluronic acid, organic acids, oligosaccharides and polysaccharide, and polyhydroxyalkanoates (Rehm, 2008). Micro organisms are beneficial for microbial biodegradation or bioremediation of domestic, agricultural and industrial wastes and subsurface pollution in soils, sediments and marine environments. The ability of each microorganism to degrade toxic waste depends on the nature of each contaminant. Since sites typically have multiple pollutant types, the most effective approach to microbial biodegradation is to use a mixture of bacterial species and strains, each specific to the biodegradation of one or more types of contaminants (Diaz, 2008). There are also various claims concerning the contributions to human and animal health by consuming probiotics (bacteria potentially beneficial to the digestive system) and/or prebiotics (substances consumed to promote the growth of probiotic microorganisms) (Tannoch, 2005).

\section{Conclusion}

Microbiology is a broad term which includes virology, mycology, parasitology, bacteriology, immunology and other branches. A microbiologist is a specialist in microbiology and these related topics. Microbiology made many contributions for the development of molecular biology also. Microorganisms serve as specific agents for large scale chemical transformations, especially variety of geochemical changes. Winogradsky and Beijerink proved that microbes play important role in the Carbon cycle, Nitrogen cycle, Sulphur cycle etc. they also proved the role of microorganism in the fixation of atmospheric nitrogen fixation (Mengesha, 2009).Microbiology contributed significantly to the development of new branches like biochemistry and Genetics. Microorganisms are responsible for the manufacture of various foods for man. The biochemical reactions of microorganism helps in the process of production of foods like Curd, Bread, Alochol, Soya Souce, SCP protein etc. the fruiting bodies of some fungi like Agaricus, Plurotus etc are used as mushrooms, SCP protein are synthesized from culturing of micro organisms like Chlorella, Spirulina, Yeasts etc. The studies on microorganisms helped in the discovery of vitamins, enzyme. Microorganism helps in several industries like medicine industry, jute industry. Hormones, Vitamins, Vaccines are also manufactured from microorganisms. They also used in Recombinant technology, cell fusion technology etc. Hence the branch microbiology developed into an independent modern branch of science.

\section{References}

Burkovski A. 2008. Corynebacteria: Genomics and Molecular Biology. Caister Academic Press.

Diaz E (ed). 2008. Microbial Biodegradation: Genomics and Molecular Biology ,Caister Academic Press.

Dundas, Paul 2002 Ibid. pp. 88

Dundas, Paul; John Hinnels 2002. The Jain. London: Routledge, pp. 24

Fracastoro, Girolamo 1546. De Contagione et Contagiosis Morbis transl. Wilmer Cave Wright (1930). New York: G.P. Putnam's.

Jaini, Padmanabh 1998. The Jaina Path of Purification. New Delhi, pp. 109.

Madigan M, Martinko J 2006 Brock Biology of Microorganisms Pearson Education. pp. 1096. 
Sethi and Madan

Mengesha 2009. "Clostridia in Anti-tumor Therapy". Rehm BHA 2008. Microbial Production of Biopolymers and Clostridia: Molecular Biology in the Post-genomic Era. Caister Academic Press.

Polymer Precursors: Applications and Perspectives. Caister Academic Press.

R.P.Singh 2009. Microbiology, Meerut, Kalyani Publishers

Rice G 2007. "Are Viruses Alive?". Retrieved 07-23.

Tannock GW 2005. Probiotics and Prebiotics: Scientific Aspects. Caister Academic Press. 